a lecturer. Now the University and citizens of Padua desire to celebrate the tercentenary of the day on which he delivered his first lecture.

When elected by the Venetian Republic to the Chair of Mathematics on September 26, 1592, he asked to be permitted to delay the beginning of his lectures in order to prepare his inaugural oration, and to attend to some domestic duties which required his presence in the country; thus it was December 7 when he first occupied the professorial chair. This date is confirmed by a letter, written from Padua to Tycho Brahe, and published by the latter in his celebrated "Astronomiæ Instauratæ Mechanica," and Galileo's chair is amongst the most precious relics preserved by the ancient and famous University. A week later he began regular lectures, which he continued to give for eighteen years.

In the ancient archives of the University the rolls of the time when Galileo taught are in a great measure preserved, and from these we learn that, in accordance with what was prescribed by the statutes, he alternated astronomical teaching with that of Euclid and the mechanical questions of Aristotle.

The didactic activity of Galileo was not altogether confined to public teaching; it was extended, in conformity with the prescriptions of the statutes, to private teaching. How much influence he exercised in this manner is easily seen from his autographic records which have come down to us. The importance of these private lessons will appear all the greater when we reflect that they dealt not only with the subjects discussed in public, but with matters connected therewith. From contemporary documents we perceive with what precision all such subjects were taught by Galileo: the use of the geometrical and military compass, fortifications, Euclid, perspective, mechanics, geography, arithmetic, geodesy, and cosmography. As to the students, they were for the most part foreigners, namely, Poles, Germans, Danes, French,and Flemings. In the lists of private scholars we find an "illustrious Englishman"very probably Richard Willoughby, who was vicar of the University of Law and Councillor of the English nation. In his honour a stone on the wall of the University is still preserved, and, a still greater honour, a copy of the famous "Difesa" is dedicated to him with Galileo's autograph. Two Scots should also be particularly mentioned as amongst Galileo's pupils; these were John Wodderborn, who wrote a confutation of the libel of Horky against Galileo, and dedicated it to Henry Wotton, the English ambassador at Venice; also Thomas Segget, Councillor of the Scots nation, in whose "Album Amicorum," now in the Vatican library, there is also an autograph of the great philosopher. It was Seggett who received from Kepler a copy of Galileo's "Sidereus Nuncius," and who in the appendix to the "Narratio" of the same Kepler published the epigrams containing the famous "Vicisti Galilaee."

Besides the ordinary public and private lectures, Galileo held in the University some special public lectures, of which we may mention those upon the new star of October, 1604 , and those in which he announced his astronomical discoveries.

Every one tried to render Galileo's stay in Padua as pleasant to him as possible. His freedom in teaching was absolutely complete, and the strong arm of the Venetian Republic defended the professors of the University from the power of Rome. In Padua, from the first, Galileo was received with the greatest kindness; he found many faithful friends both in Paduan society and among the Venetian patricians. His salary was repeatedly increased, so that, after the presentation of the telescope, it rose to thrice the amount conceded to his predecessors. Galileo came to Padua at the age of twenty-eight and remained there during the eighteen years which were the best of his life, those

No. I 2O4, YoL, 47 ] in which he showed the greatest scientific fertility, and in which he prepared the way for all his future labours We have now reached the completion of the three centuries since Galileo began his teaching in Padua, and the University naturally considers that the anniversary should not be allowed to pass without honourable notice.

It is fitting that a celebration relating to the work of a man of science of the highest rank should have a truly national character. The King of Italy has therefore associated himself with the movement ; and the Universities, the polytechnic institutions, and the most celebrated academies of the world have been invited to send delegates. Already the Universities have in great number responded to the appeal. Mr. J. Norman Lockyer will represent the Royal Society of London, and Mr. George Howard Darwin the University of Cambridge.

As once scholars from every part of Europe came to Padua to hear the celebrated master, so now from every part of Europe the most celebrated come to honour his memory.

(Director of the National Edition of Galileo's Waro

\section{A NEW METHOD OF TREATMENT FOR} CHOLERA.

$\mathrm{I} \mathrm{N}$ the Times of the $\mathrm{I} 8 \mathrm{th}$ inst. there appears an account of a new method of treatment for cholera which, should it ultimately be proved to be founded on accurate observation and well-authenticated cases, gives results seldom, if ever, obtained by any other method during the height of a cholera epidemic. Before criticizing this new method let us see what are its essential features.

In cholera there are two main, and evidently different, indications for treatment : it is usually maintained that
the primary etiological factor in the disease is the "Comma" bacillus, which under certain conditions is enabled to live and multiply in the human intestine. There, living as an anærobic organism, it thrives especially well if, through inflammatory reaction, certain of the albuminous constituents of the blood and lymph are thrown into the intestinal tract. From or in this favourable culture medium it is enabled to produce a most virulent and readily diffusible poison, which has not only a powerful local action, but also a power common to these micro-organismal poisonous products, of acting on the nerve centres. In this way, so long as the bacillus remains alive, the supply of exudation into the intestine is kept up by the local irritant action of the poison, this being accompanied by a rapid abstraction from the blood of its watery elements, and at the same time a supply of the powerful "toxine" is maintained and diffused throughout the body. Except in very severe cases, where the paralyzing effect of the toxine on the individual cells of the tissues is extremely rapid and well marked, an effort is made by these cells to destroy the bacilli and by the special secretory cells of the intestine, kidney, and other excretory organs to eject this poison from the body. Not only so, but if the poison can, like the bacillus, be confined to, and eliminated directly from the intestine, the bacillus soon becomes unable to live, and as it multiplies and produces its toxines it is killed off by the various agencies that are conspiring to destroy it.

Up to the present all conceivable methods of treatment have been tried, and almost every drug has been pressed into the attack on cholera, but the most successful and rational attempts have been those in which the destruction of the bacillus and its poison have been aimed at, especially if this has been accompanied by the use of means for promoting the rapid secretion 
and excretion of the poison from the body. Here as in the specific infective diseases generally our want is an antiseptic that will help to kill bacteria, directly or indirectly, and that will not damage, but will even give healthy stimulation to the tissue cells.

In this new method of treatment it appears to be claimed that in certain periodate salts we have substances which act not only on the bacillus (as bactericides) in the alimentary canal, but also directly on the "toxines," bringing about their oxidation into less complex and more stable non-poisonous substances, which can be readily excreted by the kidneys, or may be got rid of directly from the intestineal tract. It is also claimed, but apparently with very little reason, that the periodate salts have some direct action on the nerves; this, however, is mere conjecture, and the arguments offered in support of this hypothesis are far from convincing. In the Times article it is stated that "there are two principal drugs employed-the crystals of periodate" (of what?) "which are powdered, and a periodate of iron. The last-named is used in such cases as demand an extra strong nerve or cardiac stimulant treatment, and where there are severe neuralgic symptoms. The first is used in several ways : first as a powder to disinfect the alimentary tract ; second as a plain water solution, prepared by boiling copiously, and used as a beverage by patients to wash out the stomach in severe vomiting, which abates as soon as the walls of the stomach begin to absorb the fluid, whereby the nervous energy is stimulated, in from two minutes to an hour or two ; for transfusion under the skin, and, in cases of collapse, into a vein, for restoration of the suspended circulation of the blood; third, an acid solution of the powdered crystals of much greater strength than the plain watery preparation is found to stimulate the liver and kidney and gall bladder, promoting a free secretion of bile."

It is supposed that by this treatment the body is flushed and sweetened as it were, and so far the treatment would be rational enough could it be thoroughly carried out Far greater reliance might have been placed on the evidence put forward had the initiator of this treatment been content to place on record facts, instead of attempting to formulate a theory for everything, as his theories whilst giving evidence of his undoubted enthusiasm, indicate only too plainly that where he gets beyond the use of the test tube he is compelled to draw largely on his imagination for many of his facts and most of his explanations.

As regards the percentage of recoveries mentioned, it must be remembered that towards the end of an epidemic the fatal cases always form a much smaller proportion of the total cases than during the earlier stages of the outbreak. The people most susceptible to the attack of the disease, i.e. those with damaged hearts, kidneys, and lungs, have already succumbed, the weaklings have been cleared out of the way, and but the fittest and comparatively well-nourished remain. Attempts have been made to ameliorate the wretched surroundings of those most prone to take the disease; the poor are better fed and better able to withstand the ravages of the cholera organism; the "cholera fright," at first a most potent factor in the preparation of patients for cholera, has to some extent subsided; the cases are not only much less numerous, but they are of a milder type and a less fatal character. Then, too, after the first few batches of patients come in (amongst which the mortality is always extremely high) there ensues a kind of panic amongst the authorities, and the treatment consists of little more than placing the patient in a ward along with others suffering from the same disease, in order to get them away from their healthy companions; other treatment is for long of the most meagı description, and it is only when hygienic conditions have been improved, mode of transport organized, and hospital accommodation arranged that the

$$
\text { NO. I 2O4. VOL. 47] }
$$

medical authorities have time to devote to the treatment of individual patients. As soon as patients do obtain such individual treatment and attention the percentage of fatal cases rapidly declines.

These periodates, analogous salts to the chlorates, are apparently the direct heirs to the qualities that at one time were ascribed to the chlorates, for which it was claimed that they had great power of supplying oxygen for the transformation of poisonous products in the body. It was found, however, that these chlorates when administered in large doses made their appearance in the secretions in a very slightly altered condition ; not only so, but they exerted an exceedingly deleterious effect on the blood, reducing the hæmoglobin to methæmoglobin, and stopping the respiration and bringing about a fall of the blood pressure to zero. This periodate, which is apparently extremely insoluble except in acids, may be tolerated in small doses, but its physiological action, especially when administered in large doses, can scarcely yet have been studied.

As to the action on the kidneys through the nervous system, we have as yet little or no evidence that there is any direct action of the nerves on the secretion by the kidneys except through the vaso-motor system. It is usually maintained that the suppression of urine in cholera is due primarily to the extremely low general blood-pressure owing to the rapid abstraction of the fluid elements of the blood brought about by the passage of watery stools, but also in part to the irritative action on the secreting cells of the kidney of the cholera toxines, as a result of which secretion is more or less paralyzed. In order to overcome this stoppage of excretion by the kid. neys, the practice of injecting warm normal saline solution has in recent epidemics been practised with some success, especially when boldly and repeatedly carried out. This treatment has the additional advantage that it not only supplies fluid to the parched tissues, but also increases the volume of blood on which the heart may contract and helps to wash away the specific poison. It is utilized to a very great extent in the new method described in the Times, but whether the periodates are better than common salt as a substance with which to raise the specific gravity of the warm water, yet remains to be determined. As yet the details supplied are far too meagre to allow of any definite o inion as to the value of this periodate treatment being arrived at.

It is fortunate that we have no cholera epidemic with us at present, otherwise we should have a right to complain that the Times has been made the medium through which what must be a very imperfect-and certainly from a physiological point of view-incorrect theory, has been presented to the public, and it will be well to await the exact accounts of those who have been entrusted with the carrying out of the treatment in the wards of the Seamen's Hospital, and the results of fuller chemical physiological, and therapeutic experiments, minutely detailed and recorded, before we allow ourselves to be buoyed up by hopes which, previous experience has taught us to fear, may be very summarily and completely dashed. We hope that we may have no opportunity of testing the value of this new treatment in England, but there is too much reason to fear that, abroad, opportunities in abundance will be afforded during next spring and summer.

How much of the success obtained in Hamburg is to be ascribed to the factors above mentioned, and how much to the careful treatment and nursing of confident medical men, inspired by the enthusiasm of the "inventor" or promoter of the "periodates," it is difficult to say, and we shall await with interest, but with well disciplined and chastened expectation, the report of the German doctors mentioned in the Times on the results of their observations. 